\title{
Maxillary dentoskeletal changes 1-year after adenotonsillectomy
}

\author{
Valerio Brunelli a , Roberta Lione a , Lorenzo Franchi b,c, Paola Cozza ${ }^{a}$, Helena M.G. Becker ${ }^{\mathrm{d}}$, \\ Letícia P. Franco ${ }^{\mathrm{d}}$, Bernardo Q. Souki d,e,* \\ a Department of Clinical Sciences and Traslational Medicine, University of Rome "Tor Vergata", Rome, Italy \\ ${ }^{\mathrm{b}}$ Department of Surgery and Translational Medicine, Orthodontics, University of Florence, Florence, Italy \\ c Thomas M. Graber Visiting Scholar, Department of Orthodontics and Pediatric Dentistry, School of Dentistry, The University of Michigan, Ann Arbor, United \\ States \\ d Outpatient Clinic for Mouth-Breathers, Federal University of Minas Gerais, Belo Horizonte, Brazil \\ e School of Dentistry, Orthodontics, Pontifical Catholic University of Minas Gerais, Belo Horizonte, Brazil
}

\section{A R T I C L E I N F O}

\section{Article history:}

Received 10 February 2016

Received in revised form 20 April 2016

Accepted 21 April 2016

Available online 26 April 2016

\section{Keywords:}

Mouth breathing

Adenoids

Tonsils

Palatal morphology

Cephalometrics

\begin{abstract}
A B S T R A C T
Objective: To measure the maxillary dentoskeletal and soft tissue changes of severely obstructed mouth breathing (MB) young children who had their mode of breathing normalized after adenotonsillectomy (T\&A), in comparison with a matched group of severely obstructed untreated MB children (CG).

Methods: Seventy patients who had an Ear, Nose, and Throat examination (ENT), including flexible nasal endoscopy, to confirm the severe obstruction of the upper airways and the indication of T\&A composed the sample. Cephalograms and dental casts were available from the patient's orthodontic records. Treatment group (TG) and CG included 35 children each. Groups were matched by gender (24 males and 11 females in each group), age (TG, $6.7 \pm 1.8$ years; CG, $6.9 \pm 2.3$ years), tooth development (TG, 13 primary dentition, 22 mixed dentition; CG, 14 primary dentition, 21 mixed dentition), and skeletal maturation status. Records were taken at baseline (T0) and 1-year after T\&A (T1) for TG; while CG records were taken with a 1-year interval. Dentoskeletal measurements were performed in the lateral cephalograms, and dental casts were used to assess the palatal volume and occlusal changes.

Results: TG showed a significant increase $\left(503.3 \mathrm{~mm}^{3}, \mathrm{P}<0.001\right)$ in the palatal volume (10\% of change), while CG palatal volume was stable. No dimensional occlusal changes were detected between T0 and T1 in both groups. Significant downward (point A, $2.1 \mathrm{~mm}$; ANS, $2.1 \mathrm{~mm}$ ) and forward displacements (point A, $0.7 \mathrm{~mm}$; ANS, $1 \mathrm{~mm}$ ) of the anterior region of the maxilla were observed in the TG, but CG presented only significant downward displacement (point A, $1.8 \mathrm{~mm}$; ANS, $1.4 \mathrm{~mm}$ ). The maxillary posterior region (PNS, PTM, and Molar) displaced downward in both groups $(\mathrm{P}<0.05)$, however no sagittal change was found. The palatal plane inclination was stable in both groups.

Conclusions: TG presented significant increase in the palatal volume and in the forward displacement of the maxilla. No other significant maxillary dentoskeletal changes were found.
\end{abstract}

(c) 2016 Elsevier Ireland Ltd. All rights reserved.

\section{Introduction}

Despite the controversies that exist about the influence of mouth breathing (MB) on dentofacial growth [1], maxillary morphological abnormalities are expected in patients with airway problems [2-8]. MB allows the tongue to set in a low position in the oral cavity, resulting in unbalanced forces between external pressure (cheeks) and internal pressure (tongue) [9]. Also, the failure of the natural process of continuous airflow through the nasal passage during

\footnotetext{
* Corresponding author at: Av. Dom Jose Gaspar, 500 Prédio 46 (Colegiado de Pós Graduação), Coração Eucarístico, CEP 30535-901 Belo Horizonte, MG, Brazil. Tel.: +55 31 32455108; fax: +55 3132455115.

E-mail address: souki.bhe@terra.com.br (B.Q. Souki).
}

breathing removes the physiological stimulus for the lateral growth of the maxilla and for lowering of the palatal vault $[4,10]$.

The most common etiology of MB in young children is the obstruction of the upper airways caused by hypertrophic adenoids and tonsils [11]. In the early years of the 20th century surgical removal of tonsils was overused [12,13], which made the Otolaryngologists (ENTs) to re-think the indications for adenotonsillectomy (T\&A), and for many decades to adopt a more conservative management of the upper airway obstructive hypertrophic tissues $[12,14]$. Today, because there is evidence that quality of life in children with a surgical indication for symptomatic adenotonsillar hypertrophy is significantly improved with T\&A [14,15], such surgical procedure is very common in children [16]. In the decision process of referring an $\mathrm{MB}$ children to T\&A, many times orthodontists are required to provide to the ENTs their opinion about the benefit of surgical approach on facial growth, dental occlusion, and quality of life [15,17]. 
Much emphasis has been given to mandibular rotation and development in $\mathrm{MB}[11,18,19]$, and to the impact of T\&A [20]. However, reports of the changes in the nasomaxillary complex and of adjacent soft tissues that are functionally involved are less frequent $[4,21]$. Moreover, investigations on the dentoskeletal changes of the maxilla after the surgical correction of the mode of breathing have been neglected, and objective data are rare [20-24]. Previous longitudinal studies have shown that surgical treatment of nasal obstruction in growing individuals may result in a facial development closer to a normal pattern $[25,26]$.

At this point, some questions still have no objective answers:

(1) Is the maxilla affected in the sagittal and vertical positions 1 -year after the T\&A?

(2) Does the palatal volume change significantly when the mouth breathing habit is interrupted?

Therefore, the aim of this retrospective study was to quantify 1-year post T\&A the changes of the maxilla in a group of children who had a normalization of the mode of breathing when compared with an untreated control group of severely obstructed MB children.

\section{Materials and methods}

Approval for this study was obtained from the Institutional Review Board of the Federal University of Minas Gerais, Belo Horizonte, Brazil. The participant's rights were protected, and informed consent was obtained according to the Ethics Committee of the Federal University of Minas Gerais.

\subsection{Population}

The sample consisted of 70 children, ranging from 3.5 to 12.9 years of age referred by pediatricians and primary care physicians to the Federal University of Minas Gerais, with a diagnosis of MB. An interview with children's parents, or guardians, asking about the quality of the children's sleep, snoring, and oral breathing confirmed the "chief complaint" of MB. Ear, Nose, and Throat (ENT) clinical and endoscopic assessment confirmed that all children presented significant airway impairment with T\&A indication. Tonsils had obstructive Brodsky and Koch [27] grades 3 and/or 4; while adenoids obstructed more than $80 \%$ of nasopharyngeal airway. None of the children had undergone T\&A previously.

At the beginning of this study, 27 children ( 22 males and 5 females) were in deciduous dentition and 43 (26 males and 17 females) presented in mixed dentition. The treatment group (TG) was comprised of those 35 children with a mean age of $6.7 \pm 1.8$ years whose surgical procedure was immediately authorized by municipality public healthy service. The control group (CG) consisted of 35 patients ( 24 males and 11 females, with a mean age of $6.9 \pm 2.3$ years) who lived in an adjacent town in the same district of TG, but who had to wait more than 1 year for the surgical authorization by the public healthy system, following another public bureaucratic protocol. CG matched the TG as to the mean age at baseline, gender distribution, cervical vertebral maturation (CVM) [28], tooth development and mean duration of observational periods (Table 1).

\section{Table 1}

Comparison of demographic characteristics in treated group (TG) and control group (CG).

\begin{tabular}{lllllll}
\hline Group & $\begin{array}{l}\text { Mean age } \\
\text { at T0 }\end{array}$ & SD T0 & $\begin{array}{l}\text { Mean age } \\
\text { at T1 }\end{array}$ & SD T1 & $\begin{array}{l}\text { Diff } \\
\text { T1-T0 }\end{array}$ & $\begin{array}{l}\text { SD Diff } \\
\text { T1-T0 }\end{array}$ \\
\hline Treated & 6.9 & 2.3 & 7.71 & 2.04 & 1.12 & 0.23 \\
Control & 6.7 & 1.8 & 8.18 & 2.01 & 1.13 & 0.33 \\
\hline
\end{tabular}

The surgical effects on mouth breathing habits of TG children were determined with the same ENT criteria used pre-surgically. Normalization of the MB pattern was confirmed by parents' report during bimonthly visits along with the 1 -year post-surgical consultations. Clinical examination, including flexible nasoendoscopy, was performed one-month post-surgery, and then approximately 1-year post-surgery. All CG patients kept their MB habit during the 1 -year period, as reported by their parents quarterly.

\subsection{Cephalometric analysis}

Standard lateral cephalometric radiographs were obtained to evaluate the skeletal characteristics of the two groups. Cephalometric records in the TG were taken before surgery (T0), and then at approximately 1 -year post-operatively (T1). For the CG corresponding cephalometric radiographs were available at baseline and approximately 1-year after (T0 and T1, respectively). For each child, both radiographs were taken with the same equipment. Cephalograms were hand-traced using a $0.3-\mathrm{mm}$ lead pencil on $0.003-\mathrm{mm}$ matte acetate tracing paper. All tracings were performed by one investigator, and subsequently re-traced by a senior investigator, in random order. If any disagreement appeared between the two investigators, a common decision was taken for the final landmark identification. The hand-traced cephalograms were scanned using a professional table scanner (HP Scanjet G4050, Palo Alto, CA, USA), with resolution set to 300 dots per inch (dpi) gray scale. Computer aided measurements were performed using ImageJ $[29,30]$.

The assessment of treatment results was based on a previously described reference system traced through craniofacial stable structures [31]. First, the stable basicranial line (SBL) was traced through the most superior point of the anterior wall of sella turcica at the junction with tuberculum sellae (point T), and of the FMN point (fronto-maxillary-nasal suture). The next step was the identification of the following 5 skeletal landmarks, as shown in Fig. 1: (1) Point A (A), (2) Anterior Nasal Spine (ANS), (3) Posterior Nasal Spine (PNS), (4) Pterygomaxillary fissure (PTM), and (5) Molar (5).

Then, the following angular and linear measurements were performed (Fig. 1):

(A) ANS-SBL: perpendicular distance of the Anterior Nasal Spine to the SBL, corresponding to the anterior height position of the maxilla.

(B) PNS-SBL: perpendicular distance of the Posterior Nasal Spine to the SBL, corresponding to the posterior height position of the maxilla.

(C) A-SBL: perpendicular distance of the A point to the SBL, corresponding to the anterior maxilla height position.

(D) 5-SBL: perpendicular distance of the most occlusal and distal cusp of the second deciduous molar or the most mesial and occlusal cusp of the first permanent molar to the SBL.

(E) PTM-SBL: perpendicular distance of the highest and most posterior point of the pterygomaxillary fissure to the SBL.

(F) ANS-SBLv: perpendicular distance of the Anterior Nasal Spine to the SBLv, line constructed orthogonally to SBL, corresponding to the anterior-posterior position of the maxilla.

(G) PNS-SBLv: perpendicular distance of the Posterior Nasal Spine to the SBLv, line constructed orthogonally to SBL, corresponding to the anterior-posterior position of the maxilla.

(H) A-SBLv: perpendicular distance of the A point to the SBLv, line constructed orthogonally to SBL, corresponding to the anterior-posterior position of the maxilla.

(I) 5-SBLv: perpendicular distance of the most occlusal and distal cusp of the second deciduous molar or the most mesial and occlusal cusp of the first permanent molar to the SBLv, line constructed orthogonally to SBL. 


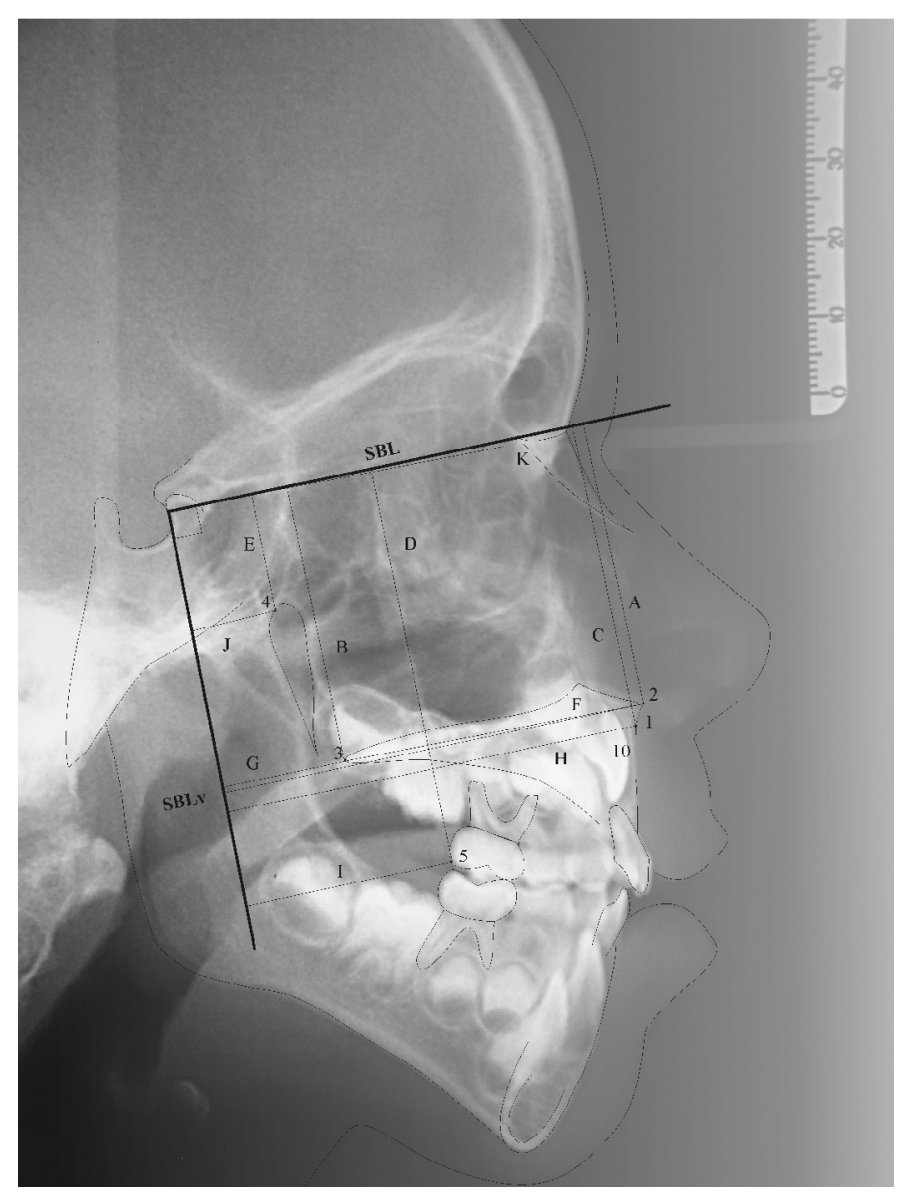

Fig. 1. Cephalometric landmarks (1-5), and linear and angular measurements (A-K).

(J) PTM-SBLv: perpendicular distance of the highest and most posterior point of the pterygomaxillary fissure to the SBLv, line constructed orthogonally to SBL.

(K) (ANS-PNS)-SBL: angular measurement between the SBL and the palatal plane (ANS-PNS). This angle measures the inclination of the palatal plane.

\subsection{Cast analysis}

Study casts were available for 41 children ( 28 for TG, and 13 for $\mathrm{CG}$ ) at T0 and T1. Five dental arch dimension measurements (maxillary intercanine width, intermolar width, dental arch length, dental arch perimeter, and palatal depth) were recorded by one examiner and checked by the senior author, as reported elsewhere [26]. A digital caliper (4 in, model 47256; Cen-Tech, Pittsburgh, PA, USA), accurate to $0.01 \mathrm{~mm}$, was used in the measurements. The evaluations were performed at T0 and repeated at T1. Measurements associated with exfoliated teeth were considered missing values for the subject.

To reduce the effect of accidental errors and improve reliability, the mean of 3 consecutive measurements, which were accepted only if they differed by less than $0.5 \mathrm{~mm}$, was used for the calculations. The correlation coefficient between the 3 measurements was greater than 0.96 for all variables.

To assess the changes in the palatal volume, a modeling compound (Play-Doh ${ }^{\circledR}$ Hasbro, Pawtucket, RI, USA) of a known density of 1.255 was used. The density $(\rho)$, of a substance is defined as the mass per unit volume. $(\rho=m / V)$, where $m$ is the mass, and $V$ is the volume. The compound molded the entire palatal concavity (Fig. 2). The most superior aspect was the palatal roof. The posterior limit was tangent to the distal surface of the maxillary right and left deciduous second molars, perpendicular to the palatal plane. The palatal plane was the most inferior aspect for the volumetric measurement, and it was constructed with the reference of the tips of the palatal cusps of the posterior teeth, and the marginal ridges of the incisors. The palatal plane was flat, as shown in Fig. 2. The mass of the compound was weighted using a professional digital scale (Analytic Scale, Gehaka, São Paulo, Brazil). With both $m$ and $\rho$, it was calculated the $V$ at T0 and T1.

Dental casts were scanned (3DShape R700, Great Lakes Orthodontics, Tonawanda, NY, USA), and .stl format files were transferred into 3D Slicer software [32]. Using the closest point color-coded surface distance map, with a color scale range of $2 \mathrm{~mm}$, with the sensibility of identifying $1 \mathrm{~mm}$ of change, the interactive visual analytics included graphic display assessment of the 3D changes in the palatal volume.

\subsection{Statistical analysis}

The data were analyzed using SPSS version 20.0 (SPSS Inc., Chicago, IL, USA). Based on the results of the Kolmogorov-Smirnov and Levene tests, the assumptions of normality and homoscedasticity were evaluated to decide whether to use parametric (independent t-test) or non-parametric (Mann-Whitney) comparison of the means and medians of the two groups. Chi-square test and independent t-test were used to verify the similarity of T\&A and CG samples. A $\mathrm{P}<0.05$ indicated statistical significance.

To determine errors in landmark identification and measurements, 25 randomly selected head films were retraced, and repeated measurements were taken by the same investigator, and subsequently verified by the same senior investigator, in random order after an interval of at least two weeks. To determine errors in the dental arch measurements, the same examiner remeasured 52 randomly selected dental casts at least 1 month later. The operators were blinded to time period and group. Random error was calculated using Intra Class Correlation coefficient, two-way mixed model, consistency type, with a confidence interval of $95 \%$ (ICC). Systematic error (bias) was assessed using the paired t-test, for $\mathrm{P}<0.05$. The random errors were calculated using ICC, and the systematic errors (bias) were assessed using the paired t-test, for $\mathrm{P}<0.05$.

The power of the study for the independent sample $t$ test was calculated on the basis of the sample size of 2 groups and an effect size for the primary endpoint (ANS-SBL) equal to 0.68 [33]. The power was 0.80 at an alpha level of 0.05 (SigmaStat 3.5, Systat Software, Point Richmond, CA, USA).

\section{Results}

The ICC ranged from 0.87 (PTM-SBLv) to 0.98 (A-SBLv, PNS-SBL, Palatal volume). The systematic error for the linear measurements ranged from $0.004 \mathrm{~mm}$ (ANS-SBL) to $0.480 \mathrm{~mm}$ (PTM$\mathrm{SBL}$ ), for the angular measurements was 0.08 degree (PP-SBL), and for the volumetric measurement was $3.7 \mathrm{~mm}^{3}$ (palatal volume). The P-value for the paired t-test ranged from 0.117 (PTM-SBL) to 0.932 (PP-SBL) (Table 2).

At T0, the mean age of TG was 6.8 years (SD: 1.76 ), and 6.9 years (SD: 2.27) for the CG. The age distribution of the subjects in the TG and CG showed no statistical difference at T0 and T1 $(P>0.05)$. The gender distribution within the two groups was not significantly different $\left(\chi^{2}, \mathrm{P}>0.05\right)$. The homogeneity between TG and CG with regard to mean age, sex distribution, and stage of dentition at T0 permitted comparison of these groups with regard to the facial dentoskeletal change differences between $\mathrm{T} 1$ and T0 for all the variables.

One year after T\&A, it was found that: 


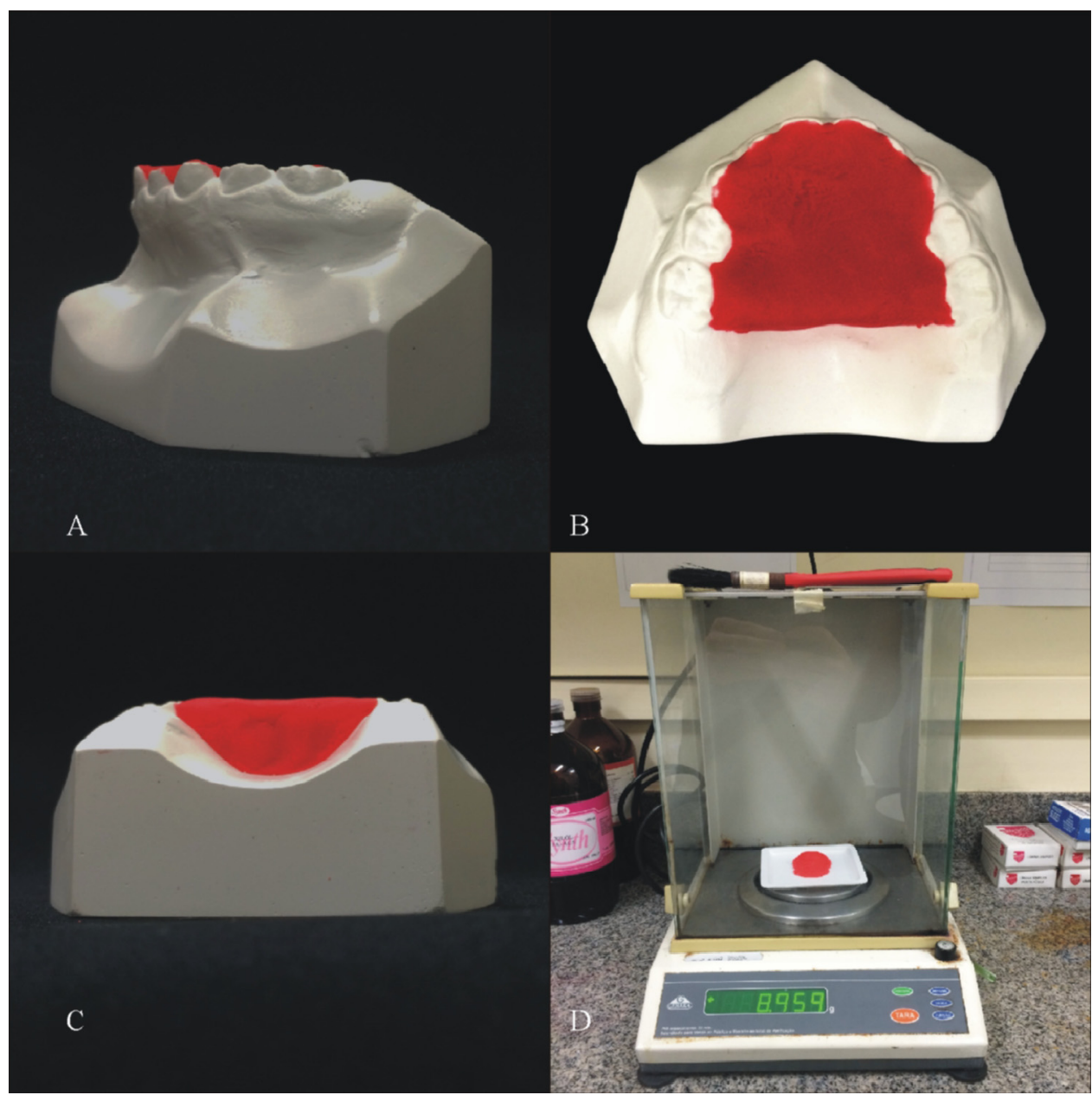

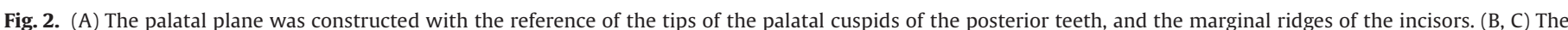

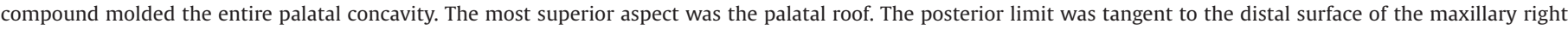
and left deciduous second molars, perpendicular to the palatal plane. (D) The mass of the compound was weighted using a professional scale.

Table 2

Reliability of cephalometric and dental cast measurements.

\begin{tabular}{|c|c|c|c|}
\hline \multirow[t]{2}{*}{ Measurement } & \multirow{2}{*}{$\begin{array}{l}\begin{array}{l}\text { Random } \\
\text { error }\end{array} \\
\text { ICC }\end{array}$} & \multicolumn{2}{|c|}{$\begin{array}{l}\text { Systematic error - } \\
\text { paired t test }\end{array}$} \\
\hline & & Error & P-value \\
\hline \multicolumn{4}{|l|}{ Dentoskeletal cephalometric measurement } \\
\hline ANS-SBL (mm) & 0.96 & 0.004 & 0.88 \\
\hline ANS-SBLv (mm) & 0.97 & 0.2 & 0.503 \\
\hline $\mathrm{A}-\mathrm{SBL}(\mathrm{mm})$ & 0.97 & 0.02 & 0.233 \\
\hline \multicolumn{4}{|l|}{ Cephalometric } \\
\hline A-SBLv (mm) & 0.98 & 0.12 & 0.641 \\
\hline PNS-SBL (mm) & 0.98 & 0.16 & 0.327 \\
\hline PNS-SBLv (mm) & 0.95 & 0.16 & 0.574 \\
\hline $5-\mathrm{SBL}(\mathrm{mm})$ & 0.97 & 0.2 & 0.38 \\
\hline 5-SBLv (mm) & 0.94 & 0.08 & 0.779 \\
\hline PTM-SBL (mm) & 0.89 & 0.48 & 0.117 \\
\hline PTM-SBLV (mm) & 0.87 & 0.04 & 0.908 \\
\hline PP-SBL (degree) & 0.97 & 0.08 & 0.932 \\
\hline \multicolumn{4}{|l|}{ Dental cast measurement } \\
\hline Palatal volume $\left(\mathrm{mm}^{3}\right)$ & 0.98 & 3.66 & 0.88 \\
\hline Maxillary intercanine width (mm) & 0.99 & 0.009 & 0.48 \\
\hline Maxillary second molar width (mm) & 0.94 & 0.129 & 0.321 \\
\hline Maxillary dental arch perimeter (mm) & 0.98 & 0.21 & 0.26 \\
\hline Palatal depth $(\mathrm{mm})$ & 0.99 & 0.03 & 0.155 \\
\hline
\end{tabular}

Notes: Data are reported as Intraclass Correlation Coefficients (ICC). Error and P-value.

\subsection{Maxilla displaced forward}

Table 2 displays the comparison of the dentoskeletal maxillary displacement between T1 and T0 in TG and CG. All the linear and angular cephalometric skeletal measurements had statistically significant changes between T0 and T1 in the TG except for PNSSBLv, PTM-SBLv and PP-SBL. With regard to that, in the CG statistically significant changes were found only in ANS-SBL, A-SBL, PTM-SBL, and PNS-SBL.

\subsection{Palatal volume increased}

Table 3 displays the comparison of the palatal volume increase between T1 and T0 in TG and CG. The palatal volume had a statistically significant change between T0 and T1 in the TG $(\mathrm{P}<0.001)$. With regard to that, in the CG no statistically significant change was found $(P=0.811)$. Comparing the changes of the dentoskeletal variables of TG and CG in the time-lapse from T0 to T1, statistically significant changes were found in PNS-SBL (P-value 0.008) and Palatal volume (P-value 0.029$)$. TG showed a higher distance between PNS and SBL than CG (1.8 mm vs. $1.1 \mathrm{~mm}$, difference $=0.7 \mathrm{~mm}$ ). Fig. 3 presents the color maps of two patients that illustrate the 3D changes of the palatal surface in MB children. Fig. 3A shows a patient from the TG, with the blue color indicating outward movement of the palatal walls along the 1-year following T\&A. Dark blue represents changes of $2 \mathrm{~mm}$, while light blue indicates $1 \mathrm{~mm}$ of outward 
Table 3

Comparison of dentoskeletal changes along the time (T1-T0) in treated group (TG) and control group (CG).

\begin{tabular}{|c|c|c|c|c|c|c|c|}
\hline Measurement & Group & $\begin{array}{l}\text { T1-T0 } \\
\text { (mean) }\end{array}$ & SD & CI 95\% & & $\begin{array}{l}\text { P-value } \\
\text { intra-group }\end{array}$ & $\begin{array}{l}\text { P-value } \\
\text { inter-groups }\end{array}$ \\
\hline \multirow[t]{2}{*}{ ANS-SBL (mm) } & TG & 2.06 & 1.19 & 1.65 & 2.46 & $<0.001$ & 0.092 \\
\hline & CG & 1.4 & 1.94 & 0.73 & 2.07 & $<0.001$ & \\
\hline \multirow[t]{2}{*}{ ANS-SBLv (mm) } & TG & 1.0 & 1.77 & 0.39 & 1.61 & 0.002 & 0.607 \\
\hline & CG & 0.74 & 2.36 & -0.07 & 1.55 & 0.071 & \\
\hline \multirow[t]{2}{*}{$\mathrm{A}-\mathrm{SBL}(\mathrm{mm})$} & TG & 2.09 & 1.63 & 1.52 & 2.64 & $<0.001$ & 0.527 \\
\hline & CG & 1.77 & 2.43 & 0.94 & 2.6 & $<0.001$ & \\
\hline \multirow[t]{2}{*}{$\mathrm{A}-\mathrm{SBLv}(\mathrm{mm})$} & TG & 0.69 & 1.78 & 0.07 & 1.3 & 0.029 & 0.537 \\
\hline & CG & 0.43 & 1.69 & -0.15 & 1.01 & 0.142 & \\
\hline \multirow[t]{2}{*}{ PNS-SBL (mm) } & TG & 1.77 & 1.09 & 1.4 & 2.14 & $<0.001$ & 0.008 \\
\hline & CG & 1.11 & 0.9 & 0.81 & 1.42 & $<0.001$ & \\
\hline \multirow[t]{2}{*}{ PNS-SBLv (mm) } & TG & -0.6 & 2.66 & -1.51 & 0.31 & 0.191 & 0.34 \\
\hline & CG & -0.09 & 1.72 & -0.68 & 0.51 & 0.77 & \\
\hline \multirow[t]{2}{*}{ 5-SBL (mm) } & TG & 2.63 & 2.49 & -3.48 & -1.77 & $<0.001$ & 0.085 \\
\hline & CG & 1.8 & 1.3 & 1.35 & 2.24 & $<0.001$ & \\
\hline \multirow[t]{2}{*}{ 5-SBLv (mm) } & TG & 1.51 & 2.59 & 0.62 & 2.41 & 0.001 & 0.142 \\
\hline & CG & 0.52 & 3.02 & -0.52 & 1.55 & 0.321 & \\
\hline \multirow[t]{2}{*}{ PTM-SBL (mm) } & TG & 0.43 & 1.22 & -0.85 & -0.01 & 0.045 & 0.308 \\
\hline & CG & 0.77 & 1.55 & -1.31 & -0.24 & 0.006 & \\
\hline \multirow[t]{2}{*}{ PTM-SBLv (mm) } & TG & 0.31 & 1.51 & -0.2 & 0.83 & 0.227 & 0.224 \\
\hline & CG & -0.08 & 1.2 & -0.5 & 0.33 & 0.675 & \\
\hline \multirow[t]{2}{*}{ PP-SBL (degree) } & TG & 0.35 & 1.78 & -0.96 & 0.26 & 0.256 & 0.67 \\
\hline & CG & 0.53 & 1.85 & -1.17 & 0.1 & 0.096 & \\
\hline \multirow[t]{2}{*}{ Palatal volume $\left(\mathrm{mm}^{3}\right)$} & TG & 503.25 & 613.56 & 265.33 & 741.16 & $<0.001$ & 0.029 \\
\hline & CG & 40.16 & 591.84 & -317.49 & 397.81 & 0.811 & \\
\hline \multirow[t]{2}{*}{ Maxillary intercanine width (mm) } & TG & 1.15 & 0.97 & 0.75 & 1.55 & $<0.001$ & 0.715 \\
\hline & CG & 0.93 & 0.46 & 0.63 & 1.23 & $<0.001$ & \\
\hline \multirow[t]{2}{*}{ Maxillary second molar width (mm) } & TG & 0.5 & 0.69 & 0.2 & 0.8 & 0.002 & 0.305 \\
\hline & CG & 0.26 & 0.46 & -0.03 & 0.56 & ns & \\
\hline \multirow[t]{2}{*}{ Maxillary dental arch perimeter (mm) } & TG & 1.06 & 3.25 & -0.26 & 2.37 & ns & 0.144 \\
\hline & CG & 2.59 & 2.11 & 1.25 & 3.94 & 0.001 & \\
\hline \multirow[t]{2}{*}{ Palatal depth (mm) } & TG & -0.17 & 0.81 & -0.5 & 0.17 & ns & 0.33 \\
\hline & CG & 0.11 & 0.34 & -0.14 & 0.34 & ns & \\
\hline
\end{tabular}

Notes: Data are reported as mean, standard deviation (SD), confidence interval (CI) difference at 95\%, and P-value.

movement of the palatal surface from T0 to T1. Fig. 3B shows a patient from the CG, with no dimensional changes along the palatal surface between T0 and T1 (predominantly green color). The exfoliation of primary teeth, and the eruption of permanent incisors and first molars are identified by the dark blue and red colors, respectively.

\subsection{Major occlusal changes were not found}

For the dental casts, statistically significant changes between T0 and T1 in the TG were found in: maxillary intercanine width $(P<0.001)$, and maxillary intermolar width $(P=0.002)$. In the $C G$ statistically significant changes happened in maxillary intercanine width as well $(\mathrm{P}<0.001)$, and maxillary dental arch perimeter
$(\mathrm{P}=0.001)$. Comparing the changes of the dentoskeletal variables of TG and CG in the time-lapse from T0 to T1, statistically significant changes were not found.

\section{Discussion}

The current investigation presents novel information to the literature, what we can expect in regard to the maxillary changes after the normalization of the mode of breathing. After analyzing the three dimensions of the maxilla of a significant sample of MB children who were exposed to two opposing situations (the normalization of the mode of breathing by means of surgical approach, and the continuation of the impaired upper airways), it was found that the palatal volume increased, and the anterior region of the maxilla

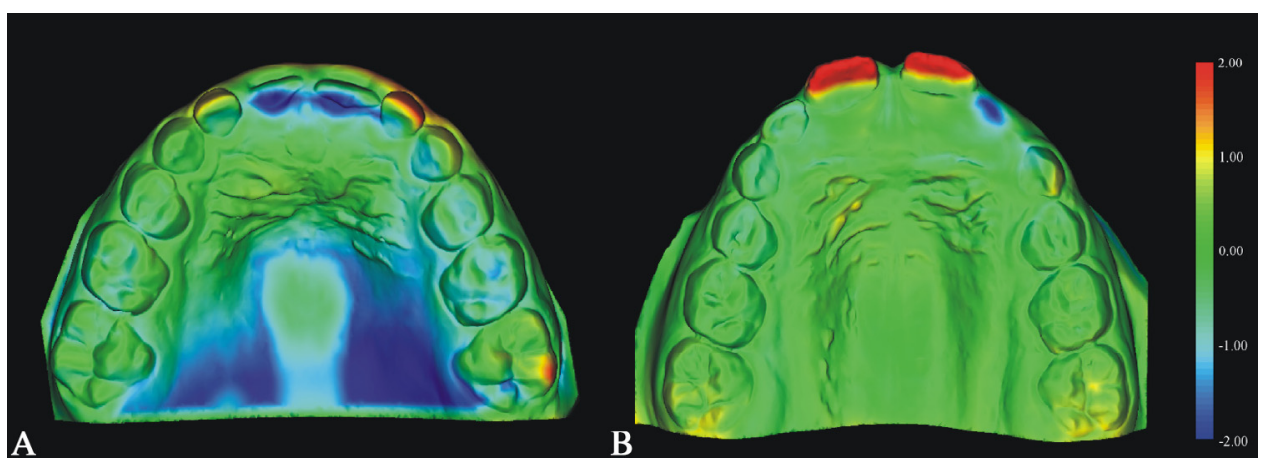

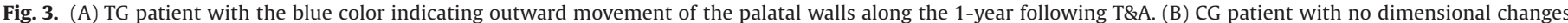

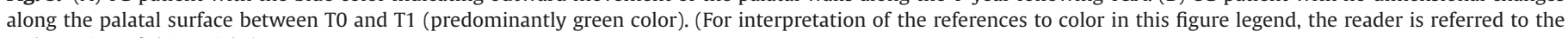
web version of this article.) 
displaced forward significantly in treated subjects. Such data can contribute to the understanding of both the etiologic participation of severe airway obstruction as well as the contribution of T\&A surgery on the developmental changes of the maxillary dentoskeletal structures and soft tissues in young growing patients. Previous studies have already demonstrated that, in comparison with nasal breathing (NB), MB children are more prone to have smaller arch dimensions, and a greater palatal depth [4,31-34]. Moreover, MB may present a lower sagittal and vertical displacement of the maxilla $[1,35,36]$. But a comprehensive 3D assessment of the impact of T\&A in the maxillary facial and dentoskeletal mid-face was not reported before.

The downward and forward displacements of the anterior part of the maxilla (ANS and point A) after 1-year of observation were statistically significant between T0 and T1 in both the TG and CG (TG, $2.1 \mathrm{~mm}$ vs. CG, $1 \mathrm{~mm}$ for ANS-SBL; TG, $1 \mathrm{~mm}$ vs. CG, $0.7 \mathrm{~mm}$ for ANS-SBLv; TG, $2.1 \mathrm{~mm}$ vs. CG, $1.8 \mathrm{~mm}$ for A-SBL; TG, $0.7 \mathrm{~mm}$ vs. CG, $0.4 \mathrm{~mm}$ for A-SBLV). However, such changes were not statistically significant in the comparison of TG and CG $(P>0.05)$. The cephalometric posterior limit of the maxilla (PNS) had a significant downward displacement in young children of both groups (TG, $1.8 \mathrm{~mm}$ vs. CG, $1.1 \mathrm{~mm}$ ), while the pterygomaxillary fissure displaced more in untreated patients (TG, $0.4 \mathrm{~mm}$ vs. CG, $0.8 \mathrm{~mm}$ ). Additionally, our results showed that restoring a correct mode of breathing did not affect sagittally the posterior region of the maxilla. In the current investigation, not any change wasfound in the sagittal position between T0 and T1 for both groups (PNS-SBLv, PTM- SBLv, P > 0.05). The pterygomaxillary fissure remained stable sagittally, in accordance with Moore [6], who reported no changes in its position when the patients are not subjected to orthodontic forces.

The position of the second deciduous molar followed the displacement of the maxilla. Changes in TG and CG were so small to be clinically and statistically discriminant (5-SBL, TG, $2.6 \mathrm{~mm}$ vs. CG, $1.8 \mathrm{~mm}, \mathrm{P}>0.085$; 5-SBLv, TG, $1.5 \mathrm{~mm}$ vs. CG, $0.5 \mathrm{~mm}, \mathrm{P}>0.142$ ).

As already reported in literature [3,4,6,26,37], the impact of upper airway obstruction on the craniofacial complex results in a retrognathic position of the jaws. We found that the normalization of the mode of breathing, in the TG, allowed the maxilla to get an increased displacement on the sagittal plane. We can infer that patients who got T\&A could benefit the forward displacement of the maxilla.

In the present investigation not any significant change was found in the dimensions of the dentoalveolar arch, both in TG and CG. The maxillary intercanine and second deciduous molar distances, and the palatal depth are fairly stable, suggesting that 1 - year after the normalization of the mode of breathing the spontaneous occlusal changes in the maxilla are not likely to happen. The dimensional changes illustrated by color mapping between surface distances from T0 to T1 in TG and CG patients clearly show that despite dental positional modifications were not found in both groups, bone remodeling can be seen in TG subjects along the palatal wall. 3D visual analysis also shows that the deepest region of the palatal roof was not modified after 1-year of T\&A, which explains why the palatal depth measurement was the same at T0 and T1, which is in agreement with previous reports [25]. However, in CG the dental arch perimeter went under a significant increase in its length compared to TG. It is probably associated with the higher proclination of the anterior teeth in the young children that were keeping the impaired mode of breathing [4]. Our data are clear on the fact that the volume of the palatal region increased significantly after T\&A. The group of patients who had undergone surgery presented a statistically significant change in the palatal volume; while the control group had only a minor increase $(P>0.811)$. Such volumetric change might be derived from the remodeling in the shape of roof of the palate, which is in accordance with Vieira et al [9] and Peltomäki [10].
The 1-year follow-up might not be enough time for all possible changes in the naso-maxillary complex, and thus a prospective clinical trial, with a longer observational period that would give more information on the additional effects. Unfortunately, a longer observational period would be not feasible in terms of a study design including a real control group, either because of the ethical issues of following up untreated patients for a long time, or because the adenotonsillar hyperplasia is a transitory condition, with a self improvement. Our findings suggested that T\&A contribute up to a certain point to the morphologic development of the maxilla after 1 -year of surgical approach, and validate previous described findings [22-24]. It is clear that the airway obstruction relief in children had some influence in the facial cranial development during the first year after the change from MB to NB.

\section{Conclusion}

Based on this study's results, the following conclusions can be made:

1. The palatal volume increased after T\&A, but spontaneous occlusal changes in the maxilla are not likely to happen;

2. The maxilla presented a significant forward displacement in young children who gained a normal mode of breathing after the T\&A;

3. No other maxillary dentoskeletal changes were found.

\section{Acknowledgments}

We thank Mrs. Luana Fialho Ferro Araujo for her time and her kind participation in the artwork, and Dr. Anna Cristina Petraconne Caixeta for her contribution in the dental cast analysis to this study. Their effort was crucial for its completion.

\section{References}

[1] P.A. Shapiro, Effects of nasal obstruction on facial development, J. Allergy Clin. Immunol. 81 (1988) 967-971.

[2] R. Joseph, The effect of airway interference on the growth and development of the face, jaws, and dentition, Int. J. Orofacial Myology 8 (1982) 4-9.

[3] A. Stellzig-Eisenhauer, P. Meyer-Marcotty, Interaction between otorhinolaryngology and orthodontics: correlation between the nasopharyngeal airway and the craniofacial complex, GMS Curr. Top. Otorhinolaryngol. Head Neck Surg. 9 (2010) Doc04

[4] A.Y. Gungor, H. Turkkahraman, Effects of airway problems on maxillary growth: a review, Eur. J. Dent. 3 (2009) 250-254.

[5] F.I. Ucar, T. Uysal, Comparison of orofacial airway dimensions in subject with different breathing pattern, Prog. Orthod. 13 (2012) 210-217.

[6] A.W. Moore, Observations on facial growth and its clinical significance, Am. J. Orthod. 45 (1959) 399-423.

[7] W.J. Kerr, J.S. McWilliam, S. Linder-Aronson, Mandibular form and position related to changed mode of breathing - a five-year longitudinal study, Angle Orthod. 59 (1989) 91-96.

[8] T.G. Shaughnessy, The relationship between upper airway obstruction and craniofacial growth, J. Mich. Dent. Assoc. 65 (1983) 431-433.

[9] B.B. Vieira, A.C.M. Sanguino, S.E. Mattar, C.E. Itikawa, W.T. Anselmo-Lima, F.C.P. Valera, et al., Influence of adenotonsillectomy on hard palate dimensions, Int. J. Pediatr. Otorhinolaryngol. 76 (2012) 1140-1144.

[10] T. Peltomäki, The effect of mode of breathing on craniofacial growth - revisited, Eur. J. Orthod. 29 (2007) 426-429.

[11] D. Harari, M. Redlich, S. Miri, T. Hamud, M. Gross, The effect of mouth breathing versus nasal breathing on dentofacial and craniofacial development in orthodontic patients, Laryngoscope 120 (2010) 2089-2093.

[12] R.C. Fairchild, A pediatrician views the tonsil and adenoid problem, Am. J. Orthod. 54 (1968) 491-494.

[13] E.S. Deutsch, Tonsillectomy and adenoidectomy. Changing indications, Pediatr. Clin. North Am. 43 (1996) 1319-1338.

[14] C.-H. Lee, K.-T. Kang, W.-C. Weng, P.-L. Lee, W.-C. Hsu, Quality of life after adenotonsillectomy in children with obstructive sleep apnea: short-term and long-term results, Int. J. Pediatr. Otorhinolaryngol. 79 (2015) 210-215.

[15] S.L. Garetz, R.B. Mitchell, P.D. Parker, R.H. Moore, C.L. Rosen, B. Giordani, et al., Quality of life and obstructive sleep apnea symptoms after pediatric adenotonsillectomy, Pediatrics 135 (2015) e477-e486.

[16] J.L. Paradise, Tonsillectomy and adenoidectomy, Pediatr. Clin. North Am. 28 (1981) 881-892. 
[17] NAMCS/NHAMCS - Ambulatory Health Care Data homepage. http://www .cdc.gov/nchs/ahcd.htm, n.d. (accessed 09.12.15).

[18] A. Kanmaz, T. Muderris, S. Bercin, M. Kiris, Children's quality of life after adenotonsillectomy, B-ENT 9 (2013) 293-298.

[19] L.P. Franco, B.Q. Souki, T.B.J. Pereira, G.M. De Brito, H.M.G. Becker, J.A. Pinto, Is the growth pattern in mouth breathers comparable with the counterclockwise mandibular rotation of nasal breathers?, Am. J. Orthod. Dentofacial Orthop. 144 (2013) 341-348.

[20] B.Q. Souki, G.B. Pimenta, L.P. Franco, H.M.G. Becker, J.A. Pinto, Changes in vertical dentofacial morphology after adeno-/tonsillectomy during deciduous and mixed dentitions mouth breathing children-1 year follow-up study, Int. J. Pediatr. Otorhinolaryngol. 74 (2010) 626-632.

[21] S. Malhotra, R.K. Pandey, A. Nagar, S.P. Agarwal, V.K. Gupta, The effect of mouth breathing on dentofacial morphology of growing child, J. Indian Soc. Pedod. Prev. Dent. 30 (2012) 27-31.

[22] K.M. Konieczny, T.C. Biggs, M.B. Pringle, A two-year follow-up observational study of the T-14 paediatric throat disorders outcome measure in tonsillectomy and adenotonsillectomy, Ann. R. Coll. Surg. Engl. 97 (2015) 382-385.

[23] B.Q. Souki, P.B. Lopes, N.C. Veloso, R.A. Avelino, T.B.J. Pereira, P.E.A. Souza, et al., Facial soft tissues of mouth-breathing children: do expectations meet reality?, Int. J. Pediatr. Otorhinolaryngol. 78 (2014) 1074-1079.

[24] R. Lione, M. Buongiorno, L. Franchi, P. Cozza, Evaluation of maxillary arch dimensions and palatal morphology in mouth-breathing children by using digital dental casts, Int. J. Pediatr. Otorhinolaryngol. 78 (2014) 9195.

[25] R. Lione, L. Franchi, L.T. Huanca Ghislanzoni, J. Primozic, M. Buongiorno, P. Cozza, Palatal surface and volume in mouth-breathing subjects evaluated with three-dimensional analysis of digital dental casts-a controlled study, Eur. J. Orthod. 37 (2015) 101-104.

[26] A.C. Petraccone Caixeta, I. Andrade, T. Bahia Junqueira Pereira, L. Paiva Franco, H.M. Gonçalves Becker, B. Quiroga Souki, Dental arch dimensional changes after adenotonsillectomy in prepubertal children, Am. J. Orthod. Dentofacial Orthop. 145 (2014) 461-468.
[27] L. Brodsky, R.J. Koch, Bacteriology and immunology of normal and diseased adenoids in children, Arch. Otolaryngol. Head Neck Surg. 119 (1993) 821-829.

[28] T. Baccetti, L. Franchi, J.A. McNamara, The cervical vertebral maturation (CVM) method for the assessment of optimal treatment timing in dentofacial orthopedics, Semin. Orthod. 11 (2005) 119-129.

[29] A.D. Lemos, C.R.T. Katz, M.V. Heimer, A. Rosenblatt, Mandibular asymmetry: a proposal of radiographic analysis with public domain software, Dental Press J. Orthod. 19 (2014) 52-58.

[30] B.A. Nanes, Slide Set: reproducible image analysis and batch processing with ImageJ, Biotechniques 59 (2015) 269-278.

[31] I. Tollaro, T. Baccetti, L. Franchi, Mandibular skeletal changes induced by early functional treatment of Class III malocclusion: a superimposition study, Am. J. Orthod. Dentofacial Orthop. 108 (1995) 525-532.

[32] F. Simmross-Wattenberg, N. Carranza-Herrezuelo, C. Palacios-Camarero, P. Casaseca-de-la-Higuera, M.A. Martín-Fernández, S. Aja-Fernández, et al., Group-Slicer: a collaborative extension of 3D-Slicer, J. Biomed. Inform. 38 (2005) 431-442.

[33] J. Cohen, A power primer, Psychol. Bull. 112 (1992) 155-159.

[34] E. Hultcrantz, M. Larson, R. Hellquist, J. Ahlquist-Rastad, H. Svanholm, O.P. Jakobsson, The influence of tonsillar obstruction and tonsillectomy on facial growth and dental arch morphology, Int. J. Pediatr. Otorhinolaryngol. 22 (1991) $125-134$.

[35] K. Agren, B. Nordlander, S. Linder-Aronsson, L. Zettergren-Wijk, E. Svanborg, Children with nocturnal upper airway obstruction: postoperative orthodontic and respiratory improvement, Acta Otolaryngol. 118 (1998) 581-587.

[36] B. Löfstrand-Tideström, B. Thilander, J. Ahlqvist-Rastad, O. Jakobsson, E. Hultcrantz, Breathing obstruction in relation to craniofacial and dental arch morphology in 4-year-old children, Eur. J. Orthod. 21 (1999) 323-332.

[37] K. Pirilä-Parkkinen, P. Pirttiniemi, P. Nieminen, U. Tolonen, U. Pelttari, H. Löppönen, Dental arch morphology in children with sleep-disordered breathing, Eur. J. Orthod. 31 (2009) 160-167. 